Revista de

Contabilidade e

Organizações

www.rco.usp.br
DOI: http://dx.doi.org/10.11606/rco.v11i30.121748
Journal of

Accounting and

Organizations

\title{
Tomada de decisão financeira sob condições de incerteza: estudo com alunos de graduação de contabilidade e administração de empresas
}

Financial decision making under uncertainty: a study with undergraduate students on accounting and business administration

Jislene Trindade Medeiros ${ }^{\mathrm{a}}$; Alexandro Barbosa ${ }^{\mathrm{b}}$; José Dionisio Gomes da Silva ${ }^{\mathrm{b}}$; Francisco Hedson da Costa

${ }^{a}$ Universidade Federal Rural do Semi-Árido

${ }^{b}$ Universidade Federal do Rio Grande do Norte

Palavras-chave

Efeito Incerteza.

Tomada de Decisão.

Finanças Comportamentais.

Ensino em Contabilidade.

\section{Resumo}

Este estudo tem como objetivo verificar a presença do efeito incerteza nas decisões financeiras tomadas por alunos dos cursos de ciências contábeis e administração, analisando a influência do gênero no nível de aversão à incerteza. Foi aplicado questionário com base no estudo de Gneezy, List e Wu (2006) para 115 alunos dos cursos de contabilidade e administração de empresas em uma universidade pública do Nordeste do país. As evidências indicam a presença do efeito incerteza no comportamento da decisão dos estudantes da amostra. Contudo, não foram encontradas evidências de que o gênero exerce influência significativa no nível de aversão à incerteza. $\mathrm{O}$ estudo aponta que podem haver outros efeitos em geral não tratados nos testes que envolvem estudantes.

\begin{abstract}
The purpose of this study is to verify the effect of uncertainty on financial decisionmaking by undergraduate students on accounting and business administration analyzing the influence of gender on the level of uncertainty aversion. We applied a survey based on Gneezy, List e Wu (2006) to 155 undergraduate students from accounting and business administration of a Brazilian Northeast public university. Evidence indicate the presence of uncertainty effect on students' decision-making behavior. However, there was no evidence that gender has considerable influence on the level of uncertainty aversion. The research suggests however, there might be other effects which generally are not considered in similar surveys applied to undergraduate students.
\end{abstract}

Copyright (C) 2017 FEA-RP/USP. Todos os direitos reservados

\section{INTRODUÇÃO}

No processo de tomada de decisão, o fator cognitivo é um fator preponderante na escolha da melhor decisão a ser tomada (Bazerman \& Moore, 2010), principalmente, devido as decisões mais importantes envolverem risco (Gneezy, List \& Wu, 2006) e o mercado ser formado por indivíduos, que cometem erros de processamento de informação (Barberis \& Huang, 2001) e que podem agir por impulsos pouco racionais (Kahneman \& Tversky, 1979) interpretando as informações de acordo com suas crenças e valores (Santos \& Santos, 2005).

Diversos aspectos podem influenciar a tomada de decisão e estes não são absolutamente racionais. No entanto, as finanças modernas tradicionais estão embasadas na ideia de racionalidade ilimitada, em que seus agentes tomam decisões unicamente racionais. Contudo, a partir da identificação do fenômeno da aversão à perda com o trabalho de Kahneman e Tversky (1979) que investigou o comportamento humano e a maneira como as decisões são tomadas em situação de risco, vários pesquisadores passaram a investigar os vieses comportamentais quando da tomada de decisão (Melo \& Silva, 2010).

Kahneman e Tversky (1979) destacam que um dos vieses que podem interferir no processo de tomada de decisão e tendem a gerar um resultado contrário àquele desejado é o efeito incerteza.

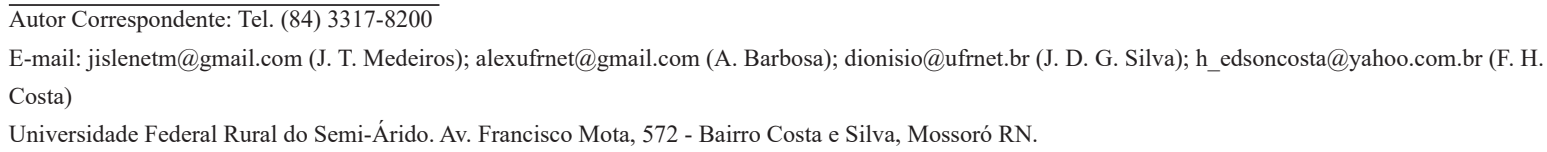


Segundo os referidos autores, esse viés está presente quando o indivíduo tem preferência por ganhos certos e, em situações em que esses são prováveis, optam pela alternativa cujo ganho tenha maior probabilidade de ocorrer. De modo semelhante, Gneezy, List e Wu (2006) defendem que o efeito incerteza é uma violação da condição de racionalidade tradicional, na medida que indivíduos tendem a avaliar a participação em sorteio por um valor inferior ao pior resultado possível para tal sorteio, ou seja, são avessos a riscos para ganhos e preferem um ganho certo a arriscar-se por tê-lo. Contadores e administradores não estariam livres de tais efeitos.

Ressalta-se que a informação contábil exerce influência no comportamento e nas crenças dos seus usuários. Contadores em geral são formados para atuarem como elaboradores ou auditores dessa informação e administradores em geral são formados para usarem tal informação na tomada de decisão. Porém, ambos, dados vieses comportamentais, não estariam lidando com dados e informações de forma neutra. Dessa forma, esse estudo busca responder ao seguinte questionamento: os alunos dos cursos de contabilidade e administração de empresas são avessos à incerteza em suas decisões financeiras e os aspectos idade e gênero influenciam essa aversão?

Assim, de modo similar ao trabalho de Kahneman e Tversky (1979), que analisou o comportamento de indivíduos que tomam decisões em ambientes marcados pelo risco e pela incerteza, a pesquisa retoma a discussão de vieses da decisão em alunos de graduação, já discutida nesta revista em Melo e Silva (2010), e em outros estudos, para comparar o efeito da aversão à incerteza entre alunos de administração e contabilidade. E ainda, se tais efeitos estariam sujeitos à influência do gênero.

Os resultados podem contribuir para a discussão tanto de estudos de finanças comportamentais no Brasil, oferecendo um caso de uma região brasileira que tem suas especificidades culturais e regionais, ajudando a compor um maior retrato do país, mas também pode contribuir com a literatura de ensino em contabilidade, na perspectiva do conteúdo ministrado e seus efeitos no comportamento frente à decisão sob risco.

\section{REFERENCIAL TEÓRICO}

Contrapondo-se a Moderna Teoria de Finanças (Fama, 1970), que se baseia em uma estrutura racional de tomada de decisão que defende que o homem é um ser perfeitamente racional, Kahneman e Tversky (1979) desenvolveram um estudo questionando a perfeita racionalidade dos agentes e investigando a existência de vieses comportamentais presentes na tomada de decisão financeira que resultou em uma teoria denominada Teoria dos Prospectos. De acordo com essa teoria, os indivíduos, no desenvolvimento do processo decisório financeiro, são avessos ao risco sob a perspectiva de ganhos e, por outro lado, propensos ao risco sob a perspectiva de perdas. Assim, o julgamento intuitivo pode ser influenciado por heurísticas, ilusões e vieses cognitivos (Melo \& Silva, 2010).

Nas últimas três décadas, pesquisadores em análise de risco, análise de decisão e economia têm consistentemente comprovado que os tomadores de decisões empregam diferentes processos para avaliar a respeito de perdas e ganhos. Embora os modelos racionais geralmente prescrevam uma resposta consistente, muitas vezes as decisões são inconsistentes com as informações fornecidas aos tomadores de decisão (Keller \& Wang, 2016; Wang, Feng \& Keller, 2013). Ao tomar uma decisão os indivíduos não conseguem analisar todas as variáveis e nem sempre as decisões são tomadas de maneira racional (Araújo \& Silva, 2007), visto que decisões importantes estão em contextos de pressão e incerteza. Assim, os tomadores de decisão comumente elaboram atalhos mentais ou as chamadas heurísticas de decisão para agilizar o processo decisório, o que interfere em sua racionalidade.

Contrariamente à abordagem clássica, o efeito incerteza está apoiado fortemente na Teoria dos Prospectos desenvolvida por Kahneman e Tversky a partir da década de 1970. Para essa teoria os indivíduos seriam avessos ao risco na dimensão dos ganhos e propensos ao risco na dimensão das perdas. Dessa forma, o efeito incerteza apresenta-se subjacente à dimensão dos ganhos, pois nesse caso os indivíduos não admitem incorrer em certos tipos ou níveis de riscos. Segundo Kahneman e Tversky (1979), em situações de incerteza em que existem diferentes níveis de retornos possíveis, a escolha do indivíduo dependerá de sua propensão ao risco para evitar perdas, sendo a aversão à perda um fator que influência significativamente a escolha do tomador de decisão.

Para reduzir as exigências de processamento de informações da tomada de decisão, principalmente em condições de incerteza, os tomadores de decisão utilizam-se de atalhos mentais para reduzir o tempo e os esforços nos julgamentos (Lima Filho et al., 2012). Os modelos de decisão sob risco, sejam eles normativos ou descritivos, assumem que os indivíduos mensuram uma perspectiva que envolve risco ou sorteio, usando algum tipo de esquema de média ponderada, avaliando, assim, entre a possibilidade de alcançarem o melhor resultado, juntamente com a possibilidade de obterem o resultado mais desfavorável (Benzion, Shahrabani \& Shavit, 2013; Gneezy, List \& Wu, 2006). 
Assim, o efeito incerteza pode ser observado, como demonstrado em Gneezy, List e Wu (2006), pela atribuição de valor feita por indivíduos que participaram de sorteios de diversos bens, quando em situações de incerteza (sorteio) estes atribuem valor inferior ao pior resultado possível em comparação ao menor valor atribuído em situações de ganho certo (certeza). Essencialmente, sob a perspetiva racional do indivíduo, o valor subjetivo da participação em um sorteio é a média ponderada dos valores de seus possíveis resultados e, como tal, deve se situar entre o valor do melhor e do pior resultado possível.

No entanto, apesar da existência de tais teorias, as quais foram propostas para explicar a aversão ao risco, é surpreendente a noção de que os indivíduos simplesmente não gostam da presença do fator de incerteza, ou seja, de que a própria incerteza influencia a utilidade (Simonsohn, 2009). Os estudos têm reexaminado o efeito incerteza em diferentes situações, além da influência do gênero no processo de tomada de decisão financeira. O Quadro 1 resume alguns desses estudos.

\begin{tabular}{|c|c|c|c|}
\hline Pesquisa & Amostra & Viés & Efeito do gênero \\
\hline Sonsino (2008) & $\begin{array}{l}107 \text { alunos de MBA em } \\
\text { administração e direito e } \\
\text { estudantes de engenharia. }\end{array}$ & $\begin{array}{c}\text { Encontrou evidências do efeito } \\
\text { incerteza nos participantes do } \\
\text { estudo }\end{array}$ & Não testado \\
\hline $\begin{array}{l}\text { Rydval et al. } \\
\quad \text { (2009) }\end{array}$ & $\begin{array}{l}214 \text { alunos de diversos cursos da } \\
\text { Charles University de Praga }\end{array}$ & $\begin{array}{c}\text { Verificou evidências do efeito } \\
\text { incerteza }\end{array}$ & Não testado \\
\hline $\begin{array}{l}\text { Simonsohn } \\
\text { (2009) }\end{array}$ & $\begin{array}{c}279 \text { alunos de uma Universidade } \\
\text { da Pensilvânia }\end{array}$ & $\begin{array}{c}\text { Indícios da existência do efeito } \\
\text { incerteza }\end{array}$ & Não testado \\
\hline $\begin{array}{c}\text { Lavarda e } \\
\text { Gubiani (2011) }\end{array}$ & $\begin{array}{l}239 \text { alunos de pós-graduação em } \\
\text { contabilidade }\end{array}$ & $\begin{array}{l}\text { Identificou a aversão ao risco } \\
\text { na área do ganho e propensão } \\
\text { ao risco na área das perdas }\end{array}$ & Não testado \\
\hline $\begin{array}{l}\text { Yang, Vosgerau } \\
\text { e Loewenstein } \\
\quad(2013)\end{array}$ & $\begin{array}{l}\text { Consumidores e vendedores da } \\
\text { Amazon Mechanical Turk }\end{array}$ & $\begin{array}{c}\text { Não se observou a existência } \\
\text { do efeito incerteza }\end{array}$ & Não testado \\
\hline $\begin{array}{l}\text { Barreto, Macedo } \\
\text { e Alves (2014) }\end{array}$ & $\begin{array}{c}155 \text { profissionais da } \\
\text { área contábil alunos de } \\
\text { pós-graduação de cinco } \\
\text { universidades }\end{array}$ & $\begin{array}{l}\text { Observou a presença do efeito } \\
\text { incerteza e framing }\end{array}$ & Não testado \\
\hline $\begin{array}{l}\text { Mahmood et al. } \\
\qquad(2016)\end{array}$ & $\begin{array}{l}477 \text { investidores individuais do } \\
\text { mercado paquistanês }\end{array}$ & $\begin{array}{l}\text { Observou um relacionamento } \\
\text { negativo entre o efeito } \\
\text { incerteza e o desempenho dos } \\
\text { investidores }\end{array}$ & Não testado \\
\hline $\begin{array}{l}\text { Schubert et al. } \\
\text { (1999) }\end{array}$ & $\begin{array}{l}141 \text { discentes de graduação } \\
\text { de diversos campos de } \\
\text { conhecimento na Suíça }\end{array}$ & Aversão à perda. & $\begin{array}{l}\text { Não verificou diferenças } \\
\text { entre homens e mulheres } \\
\text { na propensão ao risco }\end{array}$ \\
\hline $\begin{array}{l}\text { Araújo e Silva } \\
\text { (2007) }\end{array}$ & $\begin{array}{c}180 \text { estudantes de administração } \\
\text { da UnB }\end{array}$ & $\begin{array}{c}\text { Observou pouca influência } \\
\text { dos aspectos cognitivos nas } \\
\text { decisões da amostra }\end{array}$ & $\begin{array}{l}\text { Mulheres mais avessas } \\
\text { ao risco e homens } \\
\text { extremamente propensos } \\
\text { ao risco }\end{array}$ \\
\hline $\begin{array}{l}\text { Silva et al. } \\
\text { (2009) }\end{array}$ & $\begin{array}{l}216 \text { alunos de contabilidade } \\
\text { de três universidades de } \\
\text { Pernambuco }\end{array}$ & Evidenciou o efeito incerteza & $\begin{array}{l}\text { Mulheres mais avessas ao } \\
\text { risco que os homens }\end{array}$ \\
\hline $\begin{array}{l}\text { Melo e Silva } \\
\quad(2010)\end{array}$ & $\begin{array}{l}516 \text { profissionais contábeis e } \\
\text { estudantes de contabilidade }\end{array}$ & Constatou o efeito incerteza & $\begin{array}{c}\text { Alunas mulheres avessas } \\
\text { ao risco e alunos homens } \\
\text { propensos ao risco para } \\
\text { ganhos }\end{array}$ \\
\hline $\begin{array}{l}\text { Santos e Barros } \\
\quad(2011)\end{array}$ & $\begin{array}{l}641 \text { brasileiros assinantes de } \\
\text { uma revista da editora Abril }\end{array}$ & Aversão à perda. & $\begin{array}{l}\text { Mulheres mais avessas ao } \\
\text { risco que os homens }\end{array}$ \\
\hline $\begin{array}{l}\text { Vasconcelos, } \\
\text { Antunes e Silva } \\
\text { (2014) }\end{array}$ & $\begin{array}{l}1.152 \text { alunos de graduação de } \\
\text { diversos cursos e instituições na } \\
\text { cidade de Caruaru/PE }\end{array}$ & $\begin{array}{l}\text { Identificou influencia cognitiva } \\
\text { em relação as perdas e ganhos }\end{array}$ & $\begin{array}{l}\text { Não evidenciou alterações } \\
\text { quantitativas significativas }\end{array}$ \\
\hline
\end{tabular}

Quadro 1. Estudos anteriores sobre finanças comportamentais

Fonte: Elaboração própria, 2017. 
Verifica-se, com base nas pesquisas anteriores sobre finanças comportamentais relacionadas acima, que o efeito incerteza já foi evidenciado tanto em estudos nacionais como internacionais em diversas localidades. No entanto, constata-se que o efeito do gênero, ainda é um assunto pouco investigado e controverso, uma vez os resultados encontrados divergem quando a influência dessa variável na tomada de decisão financeira dos indivíduos, apesar dos estudos que evidenciaram a influência do gênero apontarem que as pessoas do gênero feminino apresentam uma aversão ao risco mais acentuada do que as do gênero masculino.

\section{PROCEDIMENTOS METODOLÓGICOS}

\subsection{Amostra e coleta dos dados}

A amostra deste estudo é composta por 115 alunos do curso de contabilidade e administração de empresas da Universidade Federal Rural do Semi-Árido, localizada na cidade de Mossoró, região Oeste do estado do Rio Grande do Norte. A cidade de Mossoró, considerada a "Capital da Cultura" do Rio Grande do Norte, é o segundo município mais populoso do Estado, atrás apenas da capital Natal, e tem como principais segmentos econômicos a fruticultura irrigada (voltada para exportação), a indústria salineira e a indústria extrativista, sendo o maior produtor de sal marinho e petróleo em terra do país.

A amostra é considerada intencional e não probabilística, visto que a escolha dos respondentes se deu por conveniência e acessibilidade dos pesquisadores, estando assim, os resultados restritos a amostra estudada. Ressalta-se que devido à amostra ter sido selecionada de maneira não aleatória, os resultados apresentados não podem ser generalizados, estando assim, os resultados restritos a amostra estudada.

Os dados colhidos nesta pesquisa foram obtidos por meio da aplicação de um questionário, elaborado com base no estudo de Gneezy, List e Wu (2006) quando os autores identificaram o efeito incerteza entre mais de 1.000 participantes de sua pesquisa. O questionário foi dividido em duas seções.

A primeira seção se refere à identificação do gênero dos respondentes. A segunda seção trouxe 13 questões divididas em três situações relacionadas com o viés da incerteza, onde em cada situação foram apresentadas duas questões com pespectivas de certeza e outras de incerteza (sorteios). Em cada uma das questões os respondentes teriam que analisar as propostas e atribuir valores com a finalidade de identificar como o risco decorrente da incerteza é incorporado no processo de tomada de decisão financeira.

\subsection{Estatística descritiva}

Dentre os 115 questionários válidos para a análise, verifica-se que 61,74\% dos respondentes são discentes do curso de ciências contábeis (71 respondentes) e 38,26\% cursam o curso de administração (44 respondentes). Na Tabela 1 são apresentados os resultados da estatística descritiva, para cada uma das situações propostas no questionário de pesquisa, como também o valor máximo e mínimo esperado para cada uma das questões. 
Tabela 1. Estatística descritiva

\begin{tabular}{|c|c|c|c|c|c|c|c|c|}
\hline \multirow[t]{2}{*}{ Situação } & \multirow[t]{2}{*}{ Questões } & \multirow{2}{*}{$\begin{array}{l}\text { Máx.-Mín. }{ }^{1} \\
\text { Esperado (E) }\end{array}$} & \multicolumn{2}{|c|}{$\begin{array}{c}\text { Todos } \\
(n=115)\end{array}$} & \multicolumn{2}{|c|}{$\begin{array}{c}\text { Contabilidade } \\
(\mathrm{n}=71)\end{array}$} & \multicolumn{2}{|c|}{$\begin{array}{l}\text { Administração } \\
(n=44)\end{array}$} \\
\hline & & & Média & Desvio* (6) & Média & Desvio* (6) & Média & Desvio* (6) \\
\hline \multirow{7}{*}{$\begin{array}{c}\text { Cartão } \\
\text { presente } \\
(\mathrm{em} \mathrm{R} \$)\end{array}$} & Q1 (C) & $50^{2} / 50$ & 32,73 & $-34,54$ & 35,83 & $-28,34$ & 27,73 & $-44,55$ \\
\hline & Q2 (C) & $100^{2} / 100$ & 65,40 & $-34,60$ & 70,06 & $-29,94$ & 57,89 & $-42,11$ \\
\hline & Q3 (S) & $99,5^{3} / 50$ & 37,57 & $-62,23$ & 41,49 & $-58,30$ & 31,26 & $-68,58$ \\
\hline & Q4 (S) & $80^{3} / 50$ & 29,52 & $-63,10$ & 32,06 & $-59,93$ & 25,43 & $-68,21$ \\
\hline & Q5 (S) & $75^{3} / 50$ & 28,16 & $-62,45$ & 30,79 & $-58,95$ & 23,92 & $-68,11$ \\
\hline & Q6 (S) & $70^{3} / 50$ & 25,75 & $-63,21$ & 28,48 & $-59,32$ & 21,36 & $-69,48$ \\
\hline & Q7 (S) & $50,5^{3} / 50$ & 24,71 & $-51,06$ & 27,33 & $-45,89$ & 20,49 & $-59,42$ \\
\hline \multirow{3}{*}{$\begin{array}{l}\text { Troca de } \\
\text { cheque } \\
(\mathrm{em} \mathrm{R} \$)\end{array}$} & Q8 (C) & $100^{2} / 100$ & 44,64 & $-55,36$ & 48,59 & $-51,41$ & 38,27 & $-61,73$ \\
\hline & Q9 (C) & $200^{2} / 200$ & 83,49 & $-58,26$ & 94,72 & $-52,64$ & 65,36 & $-67,32$ \\
\hline & Q10 (S) & $150^{3} / 100$ & 38,83 & $-74,11$ & 43,07 & $-71,29$ & 32,00 & $-78,67$ \\
\hline \multirow{3}{*}{$\begin{array}{c}\text { Tempo } \\
\text { dedicado } \\
\text { (em min) }\end{array}$} & Q11 (C) & $50^{2} / 50^{4}$ & 49,80 & $-0,40$ & 55,38 & 10,76 & 40,80 & $-18,41$ \\
\hline & Q12 (C) & $100^{2} / 100^{4}$ & 78,35 & $-21,65$ & 83,38 & $-16,62$ & 70,23 & $-29,77$ \\
\hline & Q13 (S) & $75^{3} / 50^{5}$ & 54,63 & $-27,16$ & 57,80 & $-22,93$ & 49,51 & $-33,98$ \\
\hline
\end{tabular}

Fonte: Dados da pesquisa, 2017.

$\mathrm{C}$ - situação de certeza. S - situação de incerteza (sorteio). 1 - Valor mínimo esperado = valor mínimo garantido no sorteio, caso o sorteio ocorra na alternativa mais desfavorável possível. 2 - Valor máximo esperado = (chance favorável * prêmio). No caso de Q1 R $\$ 50=100 \%$ (chance favorável) * $\mathrm{R} \$ 50$ (prêmio). 3 - Valor máximo esperado $=($ chance favorável * prêmio) + (chance desfavorável * prêmio). Em Q3, Valor máximo R $\$ 99,50=99 \%$ (chance favorável) * R \$ 50 (prêmio) $+1 \% * R \$ 50.4$ - Prêmio máximo e mínimo obtido pela permanência ouvindo a apresentação. 5 - Prêmio máximo e mínimo obtido em sorteio pela permanência ouvindo a apresentação. 6 - distorção média em relação ao cálculo racional: (resposta observada - valor máximo esperado)/valor máximo esperado. Esta distorção mostra o quanto os respondentes são mais otimistas (valores positivos) e pessimistas (valores negativos) ao se distanciarem do valor esperado racional.

A Situação 1 consiste em atribuir valores para aquisição de um Cartão Presente oferecido por uma empresa. Na questão 1 e 2 o cartão presente adquirido era de $\mathrm{R} \$ 50,00$ e $\mathrm{R} \$ 100,00$, respectivamente e as perguntas de 3 a 7 questionavam quanto os respondentes estariam dispostos a pagar para participar de sorteios concorrendo a esses cartões presentes, sendo disponibilizadas as probabilidades dos participantes ganherem $\mathrm{R} \$ 100 \mathrm{e} R \$ 50 \mathrm{em}$ cada uma das questões, onde as probabilidades de serem sorteados com o melhor prêmio (R\$100,00) são 99\%, $60 \%, 50 \%, 40 \%, 1 \%$. Entretanto, em todos os sorteios o participante seria sorteado com um Cartão Presente de no mínimo R\$50,00.

A Situação 2 é relacionada a troca de um cheque que só poderá ser sacado ao final de um ano. Na questão 8 o cheque é no valor de $\mathrm{R} \$ 100,00$, na questão 9 o cheque é no valor de $\mathrm{R} \$ 200,00$ e, a pergunta 10 questionava quanto os respondentes estavam dispostos a pagar para participar de um sorteio, onde seriam premiados com um cheque de R 100 ou R \$200. Assim, esta situação possui a mesma estrutura básica da Situação 1, mas envolvia uma escolha intertemporal.

De acordo com a Tabela 1, na amostra total e na amostra extratificada por curso, verifica-se indicativos da presença do vies da incerteza nas Situações 1 e 2 (cartão presente e troca de cheque), uma vez que as médias encontradas nas questões que envolviam sorteios (incerteza), foram inferiores ao valor mínimo em situações de certeza para cada questão.

Como os respondentes atribuem valores menores do que o mínimo possível para o sorteio, percebe-se indícios da presença do efeito incerteza tanto em alunos de contabilidade como de administração de empresas. Esses resultados sugerem que os alunos de ambos os cursos, são avessos ao risco no domínio dos ganhos e propensos ao risco no domínio das perdas, onde a maioria dos respondentes na tomada de decisão não analisou as informações disponíveis de forma lógica como o preconizado por Fama (1970). Isso indica a propensão a ganhos certos e uma aversão ao risco em consonância com o efeito incerteza, também identificado no estudo de Barreto, Macedo e Alves (2014). 
$\mathrm{Na}$ Situação 3, os respondentes teriam que dizer quanto tempo estavam dispostos a permanecerem ouvindo a apresentação de uma empresa que vende pacotes de viagens, em que de acordo com a questão onze receberiam $\mathrm{R}$ \$ 50,00 pela participação, na questão doze receberiam R \$ 100,00 e, na questão 13 participariam de um sorteio, onde ganhariam o valor de $\mathrm{R} \$ 50,00$ ou R \$ 100,00. Nesta situação, esparava-se que os respondentes no mínimo permanecessem assistindo a apresentação 1 minuto para cada $\mathrm{R} \$ 1,00$ de prêmio.

Assim, para esta questão 13 os alunos do curso de administração apresentaram o efeito incerteza, apesar da média dos valores atribuidos por esses alunos (49,5 min.) está muito próxima ao valor mínimo certo de 50 minutos. Observa-se contudo que alunos de contabilidade não apresentam o mesmo efeito, pois a média (57,80 min) é maior que 50, indicando aversão à incerteza. No caso dos alunos de contabilidade, esse resultado é similar ao encontrado por Rydval et al. (2009) e Yang, Vosgerau e Loewenstein (2013) que também não encontraram evidências do efeito incerteza em situações envolvendo sorteios.

Com base nos resultados da questão 11, verifica-se que, de modo geral, os futuros profissionais da área contábil estavam dispostos a passar mais tempo assistindo a apresentação, quase um hora (55,38 minutos) para ganhar R\$ 50,00, do que os do curso de administração para obter um ganho certo, já que em média os administradores se mostraram dispostos a permanecer por aproximadamente 41 minutos.

Desse modo, há indícios de que os alunos do curso de contabilidade, na tomada de decisão financeira, valorizam de modo mais acentuado um ganho certo e tendem a ser menos influenciados por incertezas mesmo em situações de risco quando o recurso envolvido é o próprio tempo. Os resultados sinalizam que os administradores são mais pessimistas que os alunos de contabilidade, visto que ao ponderarem sobre o valor do ganho certo e o tempo dedicado para a tomada de decisão, se descolam mais do valor esperado (cálculo racional) do que os futuros profissionais da área contábil que se mostraram menos pessimistas.

Analisando a distorção da média em relação ao valor máximo esperado em cada uma das questões, constata-se um grande desconto realizado (valores negativos na coluna 'desvio' para todas as questões, exceto a questão 11, tanto por alunos de contabilidade quanto por administradores é grande, ao ponto deles esperarem menos que o valor mínimo do ganho certo. Tal desconto significa que eles esperam receber menos que o valor mínimo possível proposto pelo teste. Mas os desvios negativos (pessimistas, avessos ao risco) são sempre maiores no caso de estudantes de administração.

De modo geral, observa-se que os alunos do curso de administração são mais pessimistas e avessos ao risco do que os alunos do curso de contabilidade, pois os descontos atribuidos pelos futuros contadores são menores, apontando que os alunos de contabilidade são mais propensos ao risco em situações que envolvem perdas e possuem uma menor avessão ao risco na tomada de decisão financeira que envolvem ganhos certos, como defendido por Kahneman e Tversky (1979), do que os futuros administradores de empresas.

\section{RESULTADOS E ANÁLISES}

\subsection{Identificação do efeito incerteza}

Na Tabela 1 pôde ser previamente observada a simples comparação entre as médias das respostas com valor mínimo racional esperado para cada questão. Já a seguir é feita uma comparação alternativa, o teste t de Student comparou as médias do menor valor atribuido pelos respondentes nas questões de ganho certo (as duas primeiras questões de cada situação) com as de sorteio, como sugerido por Gneezy, List e Wu (2006). Para a identificação da presença do viés da incerteza, as médias das questões 1 e 11 foram multiplicadas por 2 e a média da questão 9 foi dividada por 2, de modo a deixar as questões na mesma base (R\$ 100), possibilitando assim a comparação.

A Tabela 2 mostra a diferença de médias, nas situações 1, 2 e 3, demonstrando assim a presença do efeito incerteza entre os alunos dos cursos de contabilidade e administração de empresas. Os resultados apontam, uma maior valorização de um ganho certo, consequentemente, a presença da aversão ao risco.

Verifica-se que o resultado encontrado está alinhado ao observado por Gneezy, List e Wu (2006), Sonsino (2008), Simonsohn (2009), Lavarda e Gubiani (2011) e Mahmood et al. (2016). Tais resultados indicam que os indivíduos são avessos ao risco na dimensão dos ganhos, ou seja, preferem um ganho certo, o que pode ocasionar, como indicado por Mahmood et al. (2016), um desempenho menor dos investimentos realizados por esses indivíduos. 
A presença do efeito incerteza evidenciada nas três situações propostas, pode estar relacionada ao fato de que em uma decisão sob risco, como relatado por Lavarda e Gubiani (2011), os indivíduos são avessos ao risco na área do ganho e propensos ao risco na área das perdas. Ainda, devido ao defendido por Vasconcelos, Antunes e Silva (2014), as decisões dos alunos tendem a ser influenciadas pelo componente emocional das perdas e ganhos.

Ressalta-se que a diferença de médias encontradas no t de Student para a situação 3 (tempo dedicado), podem estar associada a alteração da base de identificação do viés da incerteza.

Para analisar se existem diferenças significativas entre as decisões dos alunos dos cursos de contabilidade e administração de empresas, foi utilizado o teste de Mann-Whitney. Observa-se, na Tabela 2, indicativos de que os discentes desses dois grupos, processam as informações disponíveis de modo diferente ao avaliar a respeito de perdas e ganhos como defendido por Wang, Feng e Keller (2013), visto que os alunos dos dois grupos quando expostos a situações de incerteza apresentam comportamento similar.

Esse resultado corrobora o evidenciado na Tabela 1, onde constatou-se que os alunos do curso de administração são mais sensíveis à incerteza e mais pessimistas do que os do curso de contabilidade, e mesmo quando sob certeza os alunos de administração continuam sendo pessimistas atribuindo valores mais distantes do ganho certo do que os de contabilidade, o que pode estar associado a estrutura curricular e ao perfil de formação de cada curso.

Tabela 2. Teste t de Student e Mann-Whitney para Incerteza

\begin{tabular}{|c|c|c|c|c|c|}
\hline \multirow[t]{2}{*}{ Situações } & \multirow[t]{2}{*}{ Questões } & \multicolumn{2}{|c|}{$\begin{array}{c}\text { t de Student } \\
\text { Comparação das respostas com os } \\
\text { valores de certeza (amostra com } \\
\text { todos estudantes juntos) }\end{array}$} & \multicolumn{2}{|c|}{$\begin{array}{c}\text { Mann-Whitney } \\
\text { Comparação entre as médias } \\
\text { das respostas de alunos de } \\
\text { contabilidade e administração }\end{array}$} \\
\hline & & $\mathrm{t}$ & p-valor & $\mathbf{z}$ & p-valor \\
\hline \multirow{7}{*}{$\begin{array}{c}\text { Cartão presente } \\
\quad(\mathrm{em} \mathrm{R} \$)\end{array}$} & Q1 & - & - & 2,303 & $0,021 * *$ \\
\hline & Q2 & - & - & 1,850 & $0,064 * *$ \\
\hline & Q3 & $-7,992$ & $0,000^{*}$ & 1,722 & $0,085 * * *$ \\
\hline & Q4 & $-11,085$ & $0,000^{*}$ & 1,575 & 0,115 \\
\hline & Q5 & $-11,309$ & $0,000^{*}$ & 1,560 & 0,119 \\
\hline & Q6 & $-12,488$ & $0,000^{*}$ & 1,76 & 0,115 \\
\hline & Q7 & $-12,995$ & $0,000^{*}$ & 1,676 & $0,094 * * *$ \\
\hline \multirow{3}{*}{$\begin{array}{l}\text { Troca de cheque } \\
\quad(\text { em } \mathrm{R} \$)\end{array}$} & Q8 & - & - & 1,998 & $0,046^{* * *}$ \\
\hline & Q9 & - & - & 2,618 & $0,009 * *$ \\
\hline & Q10 & $-5,888$ & $0,000^{*}$ & 0,984 & 0,325 \\
\hline \multirow{3}{*}{$\begin{array}{l}\text { Tempo dedicado } \\
\quad(\text { em min })\end{array}$} & Q11 & - & - & 1,236 & 0,216 \\
\hline & Q12 & - & - & 0,346 & 0,729 \\
\hline & Q13 & $-5,892$ & $0,000^{*}$ & 0,440 & 0,660 \\
\hline
\end{tabular}

Fonte: Dados da pesquisa, 2017.

*,** e*** denotam significância de $1 \%, 5 \%$ e $10 \%$.

\subsection{Identificação da influência do gênero no efeito incerteza}

Para verificar a influência do gênero na tomada de decisão financeira dos alunos por curso, também foi executado o teste de Mann-Whitney, para cada questão. Nas Tabela 3 e 4, são apresentados os resultados obtidos, assim como a estatística descritiva dos resultados por gênero.

Analizando o valor máximo e mínimo atribuído pelos discentes do curso de contabilidade, observase a existência de participantes tanto avessos ao risco sob a perspectiva de ganhos e propensos ao risco sob a perspectiva de perdas. Verifica-se também que os futuros contadores não incorporaram todas as informações disponíveis ao tomarem suas decisões financeiras, contrapondo-se, assim ao defendido por Fama (1970), uma vez que, com exceção da questão 13, os alunos do curso de contabilidade, de ambos os gêneros, atribuíram as questões um valor menor que o valor do ganho certo, ou seja, da pior realização possível em cada uma das situações. 
Tabela 3. Teste Mann-Whitney curso de contabilidade para o gênero

\begin{tabular}{cccccccccc}
\hline \multirow{2}{*}{ Situações } & & \multicolumn{3}{c}{ Feminino $(\mathrm{n}=23)$} & \multicolumn{3}{c}{ Masculino $(\mathrm{n}=48)$} & \multicolumn{2}{c}{ Mann-Whitney } \\
\cline { 2 - 9 } & & Média & $\begin{array}{c}\text { Desvio- } \\
\text { padrão }\end{array}$ & $\begin{array}{c}\text { Máx.- } \\
\text { Mín. }\end{array}$ & Média & $\begin{array}{c}\text { Desvio- } \\
\text { padrão }\end{array}$ & $\begin{array}{c}\text { Máx.- } \\
\text { Mín. }\end{array}$ & Z & $\begin{array}{c}\text { p } \\
\text {-valor }\end{array}$ \\
\hline & Q1 & 36,96 & 16,97 & $50-5$ & 35,29 & 17,33 & $50-0$ & $-0,528$ & 0,463 \\
& Q2 & 70,00 & 31,80 & $100-10$ & 70,08 & 33,74 & $100-4$ & 0,026 & 0,502 \\
Cartão & Q3 & 35,09 & 28,54 & $100-0$ & 44,56 & 33,10 & $100-0$ & 1,043 & 0,576 \\
presente & Q4 & 25,87 & 22,19 & $70-0$ & 35,02 & 27,05 & $100-0$ & 1,168 & 0,585 \\
(em R\$) & Q5 & 29,15 & 26,05 & $100-0$ & 31,57 & 25,02 & $100-0$ & 0,403 & 0,529 \\
& Q6 & 28,13 & 25,54 & $100-0$ & 28,64 & 22,90 & $100-0$ & 0,075 & 0,505 \\
& Q7 & 28,39 & 25,20 & $100-1$ & 26,82 & 22,07 & $100-0$ & $-0,423$ & 0,469 \\
\hline \multirow{2}{*}{$\begin{array}{c}\text { Troca de } \\
\text { cheque }\end{array}$} & Q8 & 45,65 & 35,81 & $100-0$ & 50,00 & 27,09 & $100-0$ & 0,466 & 0,534 \\
(em R\$) & Q9 & 87,39 & 68,77 & $200-0$ & 98,23 & 54,46 & $200-0$ & 0,712 & 0,552 \\
\hline \multirow{2}{*}{ Tempo } & Q10 & 40,52 & 44,86 & $150-0$ & 44,29 & 41,23 & $150-0$ & 0,593 & 0,543 \\
dedicado & Q12 & 50,43 & 73,87 & $300-5$ & 84,79 & 74,83 & $360-5$ & 0,446 & 0,533 \\
(em min) & Q13 & 58,13 & 52,57 & $180-2$ & 57,65 & 55,83 & $240-8$ & 0,190 & 0,501 \\
\hline
\end{tabular}

Fonte: Dados da pesquisa, 2017.

$*$,** e *** denotam significância de $1 \%, 5 \%$ e $10 \%$.

Observa-se na Tabela 3 que, em todas as questões, o p-valor calculado encontra-se acima de 0,05 . Dessa forma, conclui-se com $95 \%$ de confiança, que as médias dos valores atribuídos pelos alunos do curso de contabilidade do gênero feminino e masculino não são estatisticamente diferentes, ou seja, o gênero não influenciou na tomada de decisão financeira desses alunos e, consequentemente, constata-se que os alunos de ambos os gêneros possuem o mesmo nível de aversão à incerteza e de valorização do ganho certo.

Na Tabela 4 observa-se o mesmo efeito para os alunos do curso de administração de empresas. Os valores atribuídos as questões de cada situação proposta estão abaixo do valor de sua pior realização posssível (menor que o valor do ganho certo), sinalizando que os respondentes na tomada de decisão financeira não se guiaram exclusivamente pelo resultado financeiro e pelas probabilidades de ganho certo, sendo influenciados por viéses cognitivos, conforme indicado por Kahneman e Tversky (1979). Os resultados indicam que os alunos não incorporaram todas as informações disponíveis ao tomarem suas decisões contrapondo-se assim ao defendido por Fama (1970) e alinhado ao encontrado por Kahneman e Tversky (1979).

Tabela 4. Teste Mann-Whitney curso de administração para o gênero

\begin{tabular}{cccccccccc}
\hline \multirow{2}{*}{ Situações } & & \multicolumn{3}{c}{ Feminino $(\mathrm{n}=19)$} & \multicolumn{3}{c}{ Masculino $(\mathrm{n}=25)$} & \multicolumn{2}{c}{ Mann-Whitney } \\
\cline { 3 - 10 } & & Média & $\begin{array}{c}\text { Desvio- } \\
\text { padrão }\end{array}$ & $\begin{array}{c}\text { Máx.- } \\
\text { Mín. }\end{array}$ & Média & $\begin{array}{c}\text { Desvio- } \\
\text { padrão }\end{array}$ & $\begin{array}{c}\text { Máx.- } \\
\text { Mín. }\end{array}$ & Z & p-valor \\
& Q1 & 28,26 & 20,95 & $50-0$ & 27,32 & 18,31 & $50-0$ & $-0,085$ & 0,493 \\
& Q2 & 60,63 & 37,72 & $100-2$ & 55,80 & 35,96 & $100-0$ & $-0,542$ & 0,453 \\
Cartão & Q3 & 37,00 & 35,31 & $100-0$ & 26,90 & 23,60 & $80-0$ & $-0,466$ & 0,459 \\
presente & Q4 & 31,39 & 33,07 & $100-0$ & 20,90 & 17,25 & $60-0$ & $-0,369$ & 0,467 \\
(em R\$) & Q5 & 28,21 & 28,66 & $100-0$ & 20,66 & 16,91 & $60-0$ & $-0,310$ & 0,473 \\
& Q6 & 23,74 & 22,59 & $70-0$ & 19,56 & 17,33 & $60-0$ & $-0,286$ & 0,475 \\
& Q7 & 21,25 & 20,72 & $50-0$ & 19,92 & 16,83 & $50-0$ & 0,024 & 0,502 \\
\hline \multirow{2}{*}{$\begin{array}{c}\text { Troca de } \\
\text { cheque }\end{array}$} & Q8 & 30,58 & 30,76 & $100-0$ & 44,12 & 34,46 & $100-0$ & 1,484 & 0,629 \\
(em R\$) & Q10 & 58,63 & 62,62 & $200-0$ & 70,48 & 60,82 & $200-0$ & 0,897 & 0,579 \\
\hline \multirow{2}{*}{$\begin{array}{c}\text { Tempo } \\
\text { dedicado }\end{array}$} & Q11 & 44,68 & 34,93 & $100-0$ & 33,76 & 32,64 & $100-0$ & 0,945 & 0,583 \\
\hline (em min) & Q12 & 72,37 & 63,21 & $240-0$ & 68,60 & 40,58 & $150-0$ & 0,388 & 0,534 \\
\hline F & 53,74 & 48,75 & $160-1$ & 46,30 & 30,80 & $120-0$ & $-0,024$ & 0,498 \\
\hline
\end{tabular}

Fonte: Dados da pesquisa, 2017.

$*, * *$ e *** denotam significância de $1 \%, 5 \%$ e $10 \%$. 
O gênero não influencia na percepção de incerteza, seja para alunos de contabilidade ou de administração. Esses resultados são similares a Vasconcelos, Antunes e Silva (2014) e Schubert et al. (1999). Porém, são contrários ao verificado por Santos e Barros (2011), Melo e Silva (2010) e Silva et al. (2009), que constataram que os indivíduos do gênero feminino são mais avessos ao risco do que os do gênero masculino.

Essa divergência pode estar associada ao fato do instrumento de pesquisa abordar situações e bases de comparações diferentes dos estudos de Melo e Silva (2010) e Silva et al. (2009), assim como pode estar relacionada aos indivíduos da amostra aqui investigada estar inserida em uma realidade distinta da amostra desses estudos, pois o processo de tomar uma decisão é influenciado por fatores ambientais, uma vez que às preferências dos indivíduos, por ser uma atividade humana, depende da formação, experiência/vivência e das crenças e valores de cada um.

\section{CONSIDERAÇÕES FINAIS}

Verificou-se a presença do efeito incerteza, seja para alunos dos cursos de contabilidade ou de administração. Observou-se, preferência por perspectiva de menor risco (ganhos) em comparação ao valor mais desfavorável esperado. Os indivíduos não admitiram incorrer em certos tipos ou níveis de risco. Nos testes o gênero não influenciou na tomada de decisão sob condições de incerteza.

Os resultados encontrados sugerem que existe um importante efeito do background, mesmo quando a amostra envolve alunos. Ainda que os alunos sejam indivíduos em estágio de formação profissional os efeitos cognitivos na tomada de decisão financeira sob condições de incerteza, já podem ser evidenciados. Contudo, não significa necessariamente que o curso (sequência e conteúdo de disciplinas, didática, etc.) esteja exercendo um efeito isolado na propensão ao risco e incerteza, mas que também características prévias (ex. traços de personalidade) dos candidatos aos cursos de contabilidade e de administração podem importar.

A limitação da pesquisa passa pelo uso de questionário, ao invés da realização de um experimento. Além disso, é possível que os respondentes expostos a situações que envolvessem desembolsos de valores monetários reais tomassem decisões diferentes das escolhidas nesse estudo baseado em situações hipotéticas.

Sugere-se a realização de pesquisas futuras sobre outros vieses comportamentais com o objetivo de verificar como as variáveis aqui investigadas e também como outras variáveis podem interferir na tomada de decisão financeira, tais como: curso, idade, área de atuação, conservadorismo, grau de conhecimento de finanças dentre outras.

\section{REFERÊNCIAS}

Araújo, D. E., \& Silva, C. A. T. (2007). Aversão à perda nas decisões de risco. Revista de Educação e Pesquisa em Contabilidade, 1 (3), 45-62.

Barberis, N., Huang, M., \& Santos, T. (2001). Prospect theory and asset prices. The Quarterly Journal of Economics, v. 116, n. 1, p. 1-53, 2001.

Barreto, P. S., Macedo, M. A. S., \& Alves, F. J. S. (2014) Efeitos framing e certeza sob a ótica da tomada de decisão em ambiente contábil. Revista de Administração, Contabilidade e Economia da FUNDACE, 5 (2), 1-16.

Bazerman, M. H., \& Moore, D. (2010). Processo decisório. 7. ed. Rio de Janeiro: Elsevier.

Benzion, U., Shahrabani, S., \& Shavit, T. (2013). Retesting the Uncertainty Effect Using Lotteries with Real Products and Money. Bulletin of Economic Research, 65, 175-186.

Fama, E. F. (1970). Efficient capital markets: a review of theory and empirical work. The Journal of Finance, 25 (2), 383-417.

Gneezy, U., List, J., \& Wu, G. (2006). The uncertainty effect: when a risky prospect is valued less than its worst possible outcome. Quarterly Journal of Economics, 121 (4), 1.283-1.309.

Kahneman, D., \& Tversky, A. (1979). Prospect theory: an analysis of decision under risk. Econometrica, 47 (2), 263-292.

Keller, R, \& Wang, Y. (2016). Information Presentation in Decision and Risk Analysis:

Answered, Partly Answered, and Unanswered Questions. Risk Analysis, 1-14. 
Lavarda, C. E. F., \& Gubiani, C. A. (2011). O efeito reflexão na tomada de decisão orçamentária de alunos de programas de pós-graduação em Ciências Contábeis do Brasil. In: Congresso USP de Controladoria e Contabilidade, 11, 2011, São Paulo. Anais...São Paulo: Congresso UPS, CD-ROM.

Lima Filho, R. N., Bruni, A. L., \& Sampaio, M. S. (2012). A influência do gênero, idade e formação na presença de heurísticas em decisões de orçamento: um estudo quase experimental. Revista Universo Contábil, 8 (2), 103-117.

Mahmood, Z., Kouser, R., Abbas, S. S., \& Saba, I. (2016). The effect of hueristics, prospect and herding factors on investment performance. Pakistan Journal of Social Sciences - PJSS, 26 (1), 475-484.

Melo, C. L. L., \& Silva, C. A. T. (2010). Finanças comportamentais: Um estudo da influência da faixa etária, gênero e ocupação na aversão à perda. Revista de Contabilidade e Organizações, 4 (8), 3-23.

Rydval, O., Ortmann, A., Prokosheva, S., \& Hertwig, R. (2009). How certain is the uncertainty effect? Experimental Economics, 12 (4), 473-487.

Santos, J. O., \& Barros, C. A. S. (2011). O que determina a tomada de decisão financeira: razão ou emoção? Revista Brasileira de Gestão de Negócios, 13 (38), 7-20.

Santos, J. O., \& Santos, J.A. R. (2005). Mercado de capitais: racionalidade versus emoção. Revista de Contabilidade e Finanças - USP, 37, 103-110.

Schubert, R., Brown, M., Gysler, M., \& Brachinger, H. W. (1999). Financial decisionmaking: are women really more risk averse? American Economic Review, v.89, p.381-385.

Silva, R. F. M., Lagioia, U. C. T., Maciel, C. V., \& Rodrigues, R. N. (2009). Finanças comportamentais: um estudo comparativo utilizando a teoria dos prospectos com os alunos de graduação do curso de ciências contábeis. Revista Brasileira de Gestão de Negócios, 11 (33), 383-403.

Simonsohn, U. (2009). Direct risk aversion: Evidence from risky prospects valued below their worst outcome. Psychological Science, 20 (6), 686-692.

Sonsino, D. (2008). Disappointment aversion in internet bidding-decisions. Theory and Decision, 64 (2-3), 363393.

Vasconcelos, A. F., Antunes, G. A., \& Silva, C. A. T. (2014). Avaliação de perdas e ganhos nas decisões financeiras: uma investigação à luz da Prospect Theory. Revista Evidenciação Contábil \& Finanças, 2 (1), 22-38.

Wang, Y., Feng, T., \& Keller, L. R. (2013). A further exploration of the uncertainty effect. Journal of Risk and Uncertainty, 47 (3), 291-310.

Yang, Y., Vosgerau, J., \& Loewenstein, G. (2013). Framing influences willingness to pay but not willingness to accept. Journal of Marketing Research, 725-738. 